\section{Automated Thinning Increases Uniformity of In-row Spacing and Plant Size in Romaine Lettuce}

\author{
Qingquan Chu ${ }^{1}$, Jiangang Liu ${ }^{1}$, Khaled Bali ${ }^{2}$, Kelly R. Thorp ${ }^{3}$, \\ Richard Smith ${ }^{4}$, and Guangyao (Sam) Wang ${ }^{5,6,7}$
}

AdDITIONAL INDEX WORDs. Lactuca sativa, automated thinner, hand thinning, plant uniformity, lettuce yield

SUMmARY. The low availability and high cost of farm hand labor make automated thinners a faster and cheaper alternative to hand thinning in lettuce (Lactuca sativa). However, the effects of this new technology on the uniformity of plant spacing and size as well as crop yield are not proven. Three experiments were conducted in commercial romaine heart lettuce fields in 2013 and 2014 in Imperial Valley, CA, to compare the effects of automated thinning and hand thinning on uniformity of inrow spacing, plant size, and crop yield. Overhead images taken at 1 week after hand thinning indicate that thinning 8 to 11 days earlier by automated thinners did not affect plant size compared with the hand thinning treatment. However, lettuce plants in the automated thinning treatment were larger than plants in the hand thinning treatment 2 to 3 weeks after hand thinning. Automated thinners increased the uniformity of in-row spacing, increased the percentage of plants with the desired in-row spacing of 24 to $32 \mathrm{~cm}$, and almost completely removed plants with an undesirable in-row spacing of 4 to $20 \mathrm{~cm}$. As a result, individual lettuce plant weight and heart weight from the automated thinning plots was significantly greater and plants were more uniform compared with the hand thinned plants. Despite increases in lettuce plant size and uniformity in all three experiments, yield benefits of automated thinning were only significant in one of the three experiments due to larger plant populations resulting from hand thinning. This study suggests that automated thinning increases lettuce plant size and uniformity and makes it possible for growers to increase plant population and crop yield by optimizing in-row spacing.

S ignificant research on and development of automated thinners was conducted in the 1960 s and 1970s due to a shortage of lowcost labor (Lillywhite et al., 2004; Siemens et al., 2012). During that

We thank Mike Sudduth and Josh Sells for their support of the project; Tony Koselka from Vision Robotics for his support on the automated thinners; and Hugo Aguilar, Daniel Buenrostro, and the harvest crew for their help on collecting plant growth and yield data.

${ }^{1}$ College of Agronomy and Biotechnology, China Agricultural University, No. 2 West Yuanmingyuan Road, Beijing 100193, China

${ }^{2}$ University of California Cooperative Extension, Imperial County, 1050 East Holton Road, Holtville, CA 92250

${ }^{3}$ U S. Arid-Land Agricultural Research Center, US. Department of Agriculture-Agricultural Research Service, 21881 North Cardon Lane, Maricopa, AZ 85138

${ }^{4}$ University of California Cooperative Extension, Monterey County, 1432 Abbott Street, Salinas, CA 93901

${ }^{5}$ Institute of Cotton Research, Shanxi Academy of Agricultural Sciences, 118 Huanghe Road, Yuncheng, Shanxi 044000, China

${ }^{6}$ Current address: Agricultural Operations, Bridgestone Americas, 4140 West Harmon Road, Eloy, AZ 85131 .

${ }^{7}$ Corresponding author. E-mail: WangSam@bfusa. com. time, nonselective and selective automated thinners were developed not only for specialty crops but also for field crops such as cotton (Gossypium hirsutum) and sugar beet (Beta vulgaris). An oscillating hoe or a rotating blade was used in nonselected thinners to remove "blocks" of plants at fixed intervals without considering the actual location of plants. When the stand before thinning was not uniform and plants were removed between set spacing, this resulted in large gaps in the rows (Siemens et al., 2012). For selective thinners, various sensors were used to detect plant locations, and excess plants were removed by hydraulically actuated knife arms (Siemens et al., 2012). The development of this equipment was halted due to availability of precision planters in cotton and sugar beet, and the higher cost of automated thinners compared with hand thinning at the time (Lillywhite et al., 2004).

In recent years, lack of skilled farm laborers and their high cost have become significant issues for the vegetable industry, forcing growers to search for mechanical means to replace manual management practices (Taylor et al., 2012). According to vegetable producers in Imperial Valley, CA, the time per person to thin 1 acre and hand thinning quality in lettuce have been declining in recent years. Development of automated thinners enables the vegetable industry to cope with the rising cost of hand labor and to move hand labor to other tasks that are not automated, such as harvesting.

Currently available automated thinners for lettuce have been developed by four companies: Agmechtronix (Silver City, NM), Blue River (Sunnyvale, CA), Foothill Packing (Somerton, AZ), and Vision Robotics (San Diego, CA). These machines employ digital cameras to identify each lettuce seedling, analyze the spacings, and remove unwanted plants by spraying them with salt, acid-based fertilizer, or herbicide. The automated thinners have been made economically possible through the development of powerful and cost-effective computers, lower-cost sensors, and small, powerful electric motors. Compared with hand thinning, these automated thinners can lower the cost and increase the speed of the thinning progress. While thousands of hectares of lettuce have been thinned using automated thinners in California and Arizona in the last 2 to

\begin{tabular}{llll}
\hline $\begin{array}{l}\text { Units } \\
\text { To convert U.S. to SI, } \\
\text { multiply by }\end{array}$ & U.S. unit & SI unit & $\begin{array}{l}\text { To convert SI to U.S., } \\
\text { multiply by }\end{array}$ \\
\hline 0.4047 & acre $(\mathrm{s})$ & $\mathrm{ha}$ & 2.4711 \\
0.3048 & $\mathrm{ft}$ & $\mathrm{m}$ & 3.2808 \\
0.0929 & $\mathrm{ft}^{2}$ & $\mathrm{~m}^{2}$ & 10.7639 \\
2.54 & inch $(\mathrm{es})$ & $\mathrm{cm}$ & 0.3937 \\
25.4 & inch $(\mathrm{es})$ & $\mathrm{mm}$ & 0.0394 \\
6.4516 & inch & $\mathrm{cm}^{2}$ & 0.1550 \\
1.1209 & $\mathrm{lb} / \mathrm{acre}$ & $\mathrm{kg}^{2} \cdot \mathrm{ha}^{-1}$ & 0.8922 \\
28.3495 & $\mathrm{Oz}$ & $\mathrm{g}$ & 0.0353 \\
$\left({ }^{\circ} \mathrm{F}-32\right) \div 1.8$ & ${ }^{\circ} \mathrm{F}$ & ${ }^{\circ} \mathrm{C}$ & $\left({ }^{\circ} \mathrm{C} \times 1.8\right)+32$
\end{tabular}


3 years, little research has been conducted on the performance of these automated thinners.

Plant spacing affects lettuce yield and quality significantly (Maboko and Du Plooy, 2009; Ririe, 1972). In both iceberg and romaine lettuce, seeds are typically sown 2.5 inches apart. Conventionally, plants are thinned at about four-leaf stage by hand hoeing to 10 - to 12 -inch in-row spacing, depending on lettuce type and growing season. Lettuce crops with in-row spacing larger than 12 inches result in a small number of harvestable plants. In contrast, lettuce crops with in-row spacing smaller than 10 inches result in large number of small hearts that often do not meet market standards (Ririe, 1972). A nonuniform stand also reduces the number of harvestable plants due to different maturity times among plants (Ririe, 1972). Maintaining lettuce uniformity is more challenging when the crop is planted during a warm period because high temperature increases plant variability in crop emergence and plant size in lettuce (Guzman, 1986). This is especially important in southern California and southwestern Arizona, where the average maximum temperature in September is $102{ }^{\circ} \mathrm{F}$ and where over $90 \%$ of U.S. wintertime lettuce is produced.

Given the rapid increase in the use of automated thinners in the lettuce industry, it is important to examine the effects of this technology on in-row spacing, plant size, and crop yield and to determine if there are ways to enhance its benefits. Therefore, the objective of this study was to compare the effects of automated thinning and hand thinning on the uniformity of in-row plant spacing, plant size after thinning and at harvest, and crop yield.

\section{Materials and methods}

EXPERIMENTAL SITE AND DESIGN. Three field experiments were carried out in growers' fields in 2013 and 2014 in Imperial County, CA. The locations and soil types for the three sites are listed in Table 1. The growing periods were 16 Sept. 2013 to $4-$ 6 Dec. 2013 (Expt. 1), 23 Nov. 2013 to 11-14 Mar. 2014 (Expt. 2), and 27 Dec. 2013 to l-2 Apr. 2014 (Expt. 3) (Table 1). Average maximum and minimum air temperature was 84.4 and $55.4^{\circ} \mathrm{F}$, respectively, for Expt. $1 ; 74.5$ and $45.1^{\circ} \mathrm{F}$, respectively, for Expt. 2; and 77.9 and $47.5^{\circ} \mathrm{F}$, respectively, for Expt. 3. Precipitation during the growing period was $0.63,0.05$, and 0.02 inches for Expts. 1,2 , and 3 , respectively.

The experiment was a randomized complete block design with four replications. Two treatments were included in each experiment: automated thinning and hand thinning. Each plot was six 80-inch-wide beds and $600 \mathrm{ft}$ long. Six rows of romaine heart lettuce were grown on each bed.

Field management. Durum wheat (Triticum durum) was grown in the field for Expt. 1, and summer sudangrass (Sorghum bicolor var. sudanense) was grown in the fields for Expts. 2 and 3 before romaine heart lettuce planting (Table 1 ). One month before each planting, tillage operations to prepare for lettuce planting included disking, ripping, disking again, laser leveling, listing, and bed shaping. Preplant fertilizer $11 \mathrm{~N}-22.7 \mathrm{P}-0 \mathrm{~K}$ was applied at $500 \mathrm{lb} /$ acre. During the growing season, $150 \mathrm{lb} /$ acre of $\mathrm{N}$ fertilizer in the form of urea ammonium nitrate (UAN 32) was split-applied to the crop with irrigation. This was significantly higher than the rate recommended by the University of California Cooperative Extension, but is commonly used in the region (Smith et al., 2011). Solid-set sprinklers were used to irrigate the crop in each field, scheduled by evapotranspiration values from local weather stations and farm manager's experience.

Romaine heart lettuce varieties Eblin, Sunbelt, and Rubicon were planted for Expts. 1, 2, and 3, respectively. Different varieties were used because they were suitable for each growing period and were chosen by the collaborating grower. Lettuce was planted with seed spacing of 2.5 inches using a precision planter $(\mathrm{Mel}$ Beck Precision Planters, Nyssa, OR). Hand thinning was done at the fourleaf stage. Automated thinning was conducted at the two-leaf stage, since current automated thinners do not move soil and thus avoid burying and damaging young plants as occurs in hand thinning operations. Additionally, thinning at an earlier stage enables the computer to visually identify lettuce plants that are spaced closely together. An automated thinner
(Vision Robotics) was used to thin the romaine heart lettuce crop. Unwanted plants were sprayed with ammonium nitrate (AN 20) or a mixture of AN 20 and ammonium thiosulfate for a total of $56 \mathrm{lb} /$ acre of N. Before the subsequent irrigation $(3-5 \mathrm{~d}$ after automated thinning), an equal amount of $\mathrm{N}$ fertilizer in the form of AN 20 was sidedressed between crop rows in plots to be hand thinned. Hand thinning was conducted $\approx 10 \mathrm{~d}$ after automated thinning. The hand labor crew thinned the field plots without being notified that their thinning accuracy would be compared with automated thinning. All other management practices, such as pesticide application and hand weeding, were conducted according to common farming practices recommended by the University of California Cooperative Extension (Smith et al., 2011).

Data collection. Plant biomass samples were collected immediately after hand thinning on 12 Oct. 2013, 24 Dec. 2013, and 25 Jan. 2014 for Expts. 1, 2, and 3, respectively. A sample of 20 lettuce plants was collected randomly from each plot. All samples were oven-dried at $160{ }^{\circ} \mathrm{F}$ with ventilation, weighed, and then ground to $0.5 \mathrm{~mm}$ for total $\mathrm{N}$ concentration analysis using an elemental analyzer (model NAl500 N/C; Carlo Erba Instruments, Milan, Italy).

One day before hand thinning, eight overhead images were taken in each plot to compare lettuce leaf area in the automated thinning plots to the nonthinned plants in the hand thinning plots. Overhead images were also taken at $1-3 \mathrm{~d}, 1$ week, and 2 weeks after hand thinning to compare plant size between the two treatments. A digital camera was attached to a straight pole and was placed $\approx 2.5 \mathrm{~m}$ over a bed to take the images. A meter stick was placed between the middle two rows in each image for plant leaf area calibration. Each image was processed using ENVI (Exelis Visual Information Solutions, McLean, VA) to separate and count the pixels of each plant. The number of pixels was used to calculate leaf area of each plant in each image using the length of the meter stick to determine the number of image pixels per meter. Mean leaf area for each plot was calculated from leaf area of all plants in the eight images. 
Table 1. Location and management information for romaine heart lettuce in the three experimental fields in Imperial Valley, CA.

\begin{tabular}{|c|c|c|c|}
\hline $\begin{array}{l}\text { Management } \\
\text { information }\end{array}$ & Expt. 1 & Expt. 2 & Expt. 3 \\
\hline Location & $\begin{array}{l}\text { lat. } 32.819912^{\circ} \mathrm{N}, \\
\quad \text { long. } 115.356532^{\circ} \mathrm{W}\end{array}$ & $\begin{array}{l}\text { lat. } 32.980603^{\circ} \mathrm{N} \text {, long. } \\
\quad 115.356144^{\circ} \mathrm{W}\end{array}$ & $\begin{array}{l}\text { lat. } 32.860986^{\circ} \mathrm{N} \text {, long } \\
115.302005^{\circ} \mathrm{W}\end{array}$ \\
\hline Previous crop & Durum wheat & Summer sudangrass & Summer sudangrass \\
\hline Romaine heart variety & Eblin & Sunbelt & Rubicon \\
\hline automated thinning date & 1 Oct. 2013 & 13 Dec. 2013 & 17 Jan. 2014 \\
\hline Hand thinning date & 12 Oct. 2013 & 24 Dec. 2013 & 25 Jan. 2014 \\
\hline $\mathrm{N}-\mathrm{P}-\mathrm{K}$ fertilizer $(\mathrm{lb} / \mathrm{acre})^{\mathrm{z}}$ & $261-115-0$ & $261-115-0$ & $261-115-0$ \\
\hline Harvest date & 4-6 Dec. 2013 & 11-14 Mar. 2014 & 1-2 Apr. 2014 \\
\hline
\end{tabular}

${ }^{2}$ Nitrogen-phosphorus-potassium; l lb/acre $=1.1209 \mathrm{~kg} \cdot \mathrm{ha}^{-1}$.

In-row spacing in both treatments was measured $1 \mathrm{~d}$ after hand thinning. The measurements were taken in a total of 21,39 , and $23 \mathrm{~m}$ of row length from the center area of each plot in Expts. 1, 2, and 3, respectively. Before commercial harvest, plants in $67 \mathrm{ft}^{2}$ (10 ft of the 80 -inchwide bed) from each plot were removed to determine the uniformity of the plant and heart weights. All lettuce plants from each sampling area were cut at the soil surface. The number of plants in each sampling area was used to estimate plant population in each plot. The fresh weights of individual plants were recorded. Each plant was then cut to simulate romaine heart harvest in the field and the heart weight was recorded. To reduce variation, all plants from each field were cut to obtain romaine hearts by the same individual.

Lettuce hearts were commercially harvested by a hand labor crew. At the time of harvest, all plots in Expt. 1 or 3 were harvested by the same crew. One of the four blocks in Expt. 2 was harvested by a different crew from the one harvesting the other three blocks due to changes in available personnel on different days. Romaine hearts were cut and packed into boxes. Each box contained 12 bags each with three romaine hearts. The number of boxes from each plot was recorded.

Data analysis. Since the three field experiments were conducted during different growing periods, data from each field are presented separately. Analysis of variance was used to compare plant biomass at hand thinning, leaf area, plant population, and crop yield. Treatment means were separated by least significant difference at the 0.05 level when appropriate. Analyses were performed using SAS (version 9.3; SAS Institute, Cary, NC).

Data on in-row spacing and lettuce plant weight at harvest were analyzed using histograms according to Bityukov et al. (2013). The data in each bin of the histogram followed a normal distribution, as confirmed by PROC Univariate procedure of SAS. Since the data in the histogram are counts, they can be considered as the approximation of a Poisson distribution by normal distribution (Bityukov et al., 2013).

For bin $i$ in histogram 1 and 2, the significance of difference is defined as

$$
\hat{S}_{i}=\frac{\hat{n}_{i 1}-\frac{N_{1}}{N_{2}} \hat{n}_{i 2}}{\sqrt{\hat{\sigma}_{n_{i 1}}^{2}+\left(\frac{N_{1}}{N_{2}}\right)^{2} \hat{\sigma}_{n_{i 2}}^{2}}}
$$

where $\hat{n}_{i 1}$ and $\hat{n}_{i 2}$ are expected values of the observations in the bin $i$ of histogram 1 and 2 , respectively; $\hat{\sigma}_{n_{i 1}}^{2}$ and $\hat{\sigma}_{n_{i 2}}^{2}$ are the variance of bin $i$ of histogram 1 and 2, respectively; and $N_{1}$ and $N_{2}$ are the total number of events in histogram 1 and 2 , respectively.

The root mean square (RMS) of the distribution of the significance is used to compare the two histograms:

$$
R M S=\sqrt{\frac{\sum_{i=1}^{M}\left(\hat{S}_{i}-\bar{S}\right)^{2}}{M}}
$$

where $M$ is the number of bins and $\bar{S}$ is the mean value of $\hat{S}_{i}$. RMS $>>1$ means that histograms are obtained from different parent distributions
(Bityukov et al., 2013). RMS $\approx 1$ means that both histograms are independent samples from the same distribution, indicating that two tested populations are not different. When two histograms are identical, $\mathrm{RMS}=0$.

\section{Results}

Plant size and thinning. Plants in the automated thinning treatment were thinned 11,11 , and $8 \mathrm{~d}$ earlier than those hand thinning plots in Expts. 1, 2, and 3, respectively (Table 1). Analysis of overhead images on the day before hand thinning showed that plants in the automated thinning treatment were not different in leaf area from nonthinned plants in hand thinning treatment, indicating that seedling growth was not changed by early automated thinning (Table 2).

One day after hand thinning, lettuce plant biomass in the automated thinning treatment was not significantly different from plant biomass in the hand thinning treatment in the Expts. 1 and 2, but was significantly higher for Expt. 3 (Table 3). Plant $\mathrm{N}$ concentration in the automated thinning plots was higher in Expt. 1, but was not different from plants in the hand thinning plots in Expts. 2 and 3. In the automated thinning treatment, the $\mathrm{N}$ fertilizer that was sprayed to kill the unwanted plants was left on the soil surface. In the hand thinning treatment, a similar amount of $\mathrm{N}$ fertilizer was sidedressed between the crop rows $3-5 \mathrm{~d}$ after the automated thinning. It seems that the delay and/or different application methods might have affected lettuce $\mathrm{N}$ concentration in Expt. 1 and plant 
Table 2. Romaine lettuce leaf area obtained from analysis of overhead images before and after hand thinning.

\begin{tabular}{|c|c|c|c|c|c|}
\hline \multirow[b]{2}{*}{ Expt. no. } & \multirow[b]{2}{*}{ Treatment } & $\begin{array}{c}\text { Leaf area at } \\
1-2 \mathrm{~d} \text { before } \\
\text { hand thinning }\end{array}$ & $\begin{array}{c}\text { Leaf area at } \\
1-3 \mathrm{~d} \text { after } \\
\text { hand thinning }\end{array}$ & $\begin{array}{c}\text { Leaf area at } \\
1 \text { wk after } \\
\text { hand thinning }\end{array}$ & $\begin{array}{r}\text { Leaf area at } \\
2-3 \text { wk after } \\
\text { hand thinning }\end{array}$ \\
\hline & & \multicolumn{4}{|c|}{$\left(\mathrm{cm}^{2} / \text { plant }\right)^{\mathrm{z}}$} \\
\hline \multirow{3}{*}{1} & Date & 10 Oct. 2013 & 12 Oct. 2013 & 18 Oct. 2013 & \\
\hline & Hand thinning & 13.91 & 25.8 & 83.3 & \\
\hline & Automated thinning & 13.98 & 26.3 & 87.8 & \\
\hline \multirow[t]{2}{*}{2} & Hand thinning & 4.53 & $6.22 \mathrm{~b}^{\mathrm{y}}$ & & $73.3 \mathrm{~b}$ \\
\hline & Automated thinning & 4.64 & $7.49 \mathrm{a}$ & & $93.6 \mathrm{a}$ \\
\hline \multirow[b]{2}{*}{3} & Date & 25 Jan. 2014 & & 31 Jan. 2014 & 7 Feb. 2014 \\
\hline & Hand thinning & 5.01 & & 17.1 & $53.1 \mathrm{~b}$ \\
\hline
\end{tabular}

${ }^{\mathrm{z}} 1 \mathrm{~cm}^{2}=0.1550$ inch $^{2}$.

${ }^{y}$ Means with different letters in the same column of each experiment are significantly different via least significant difference at $P \leq 0.05$.

Table 3. Romaine heart lettuce plant weight and nitrogen concentration $1 \mathrm{~d}$ after hand thinning.

\begin{tabular}{llcc}
\hline Expt. no. & \multicolumn{1}{c}{ Treatment } & Plant wt $(\mathrm{g} / \text { plant })^{\mathrm{z}}$ & Nitrogen concn (\%) \\
\hline 1 & Hand thinning & 0.28 & $4.39 \mathrm{~b}^{\mathrm{y}}$ \\
& Automated thinning & 0.29 & $4.56 \mathrm{a}$ \\
2 & Hand thinning & 0.078 & 3.98 \\
& Automated thinning & 0.081 & 3.82 \\
3 & Hand thinning & $0.047 \mathrm{~b}$ & 4.42 \\
& Automated thinning & $0.051 \mathrm{a}$ & 4.52 \\
\hline
\end{tabular}

${ }^{\mathrm{z}} 1 \mathrm{~g}=0.0353 \mathrm{oz}$.

'Means with different letters in the same column of each experiment are significantly different via least significant difference at $P \leq 0.05$.

size in Expt. 3. The causes of these differences in plant growth are not clear, especially since $\mathrm{N}$ fertilizer in the automated thinning treatment was only sprayed on unwanted plants and the field was not irrigated until an equal amount of $\mathrm{N}$ fertilizer was applied to the hand thinning treatment.

Three days after hand thinning, lettuce plants in the automated thinning treatment were significantly larger than the plants in the hand thinning treatments in Expt. 2 (Table 2). However, this is likely because hand thinning cut the top of many plants in the heavy clay soil of the field and the lower sections of the plants were still counted by the image processing software as plants. There were no differences in leaf area between the two treatments at 1 week after hand thinning in Expts. 1 and 3 . At 2-3 weeks after hand thinning, plants in the automated thinning treatment were larger than plants in the hand thinning treatment in Expts. 2 and 3.
IN-ROW SPACING AND THINNING. RMS values for testing the differences of two histograms from the same field experiment were $1.7,3.9$, and 1.8 for Expts. 1, 2, and 3, respectively, indicating that the distribution of inrow spacing was different in the lettuce seedlings that were automated instead of hand-thinned (Fig. 1). Automated thinning increased the uniformity of in-row spacing. Compared with hand thinning, the percentage of plants with the desired in-row spacing of 24 to $32 \mathrm{~cm}$ in automated thinning increased from $48 \%$ to $59 \%$ in Expt. 1 , from $39 \%$ to $68 \%$ in Expt. 2, and from $73 \%$ to $83 \%$ in Expt. 3. Both hand thinning and automated thinning left a small percentage of doubles (two plants that are closer than $1.2 \mathrm{~cm}$ ) in the fields. However, the automated thinner almost completely removed plants with in-row spacing of 4 to $20 \mathrm{~cm}$, leaving only $1.4 \%, 2.5 \%$, and $0.6 \%$ of plants in this range in Expts. 1, 2, and 3 , respectively (Fig. 1). In contrast, hand thinning resulted in $11 \%$, $22 \%$, and $6 \%$ of plants with in-row spacing of 4 to $20 \mathrm{~cm}$ in Expts. 1, 2, and 3 , respectively.

The wider distribution of inrow spacing in Expt. 1 was due to poor stand caused by rainfall in Sept. 2013. The heavy clay soil in Expt. 2 made hand thinning more challenging, which resulted in larger differences in in-row spacing between hand thinning and automated thinning. The growing points of many unwanted plants were not cut during thinning because of the hard soil surface. A second thinning had to be conducted 2 weeks later. The stand and soil texture in Expt. 3 were the best among the three fields in this study, resulting in better in-row spacing in both hand thinning and automated thinning treatments compared with the other two fields.

Plant and heart Weight BEFORE HARVEST. RMS values for testing the differences of two histograms in the same field experiments were 1.4, 2.7, and 1.5 for Expts. 1, 2, and 3 , respectively, indicating that distribution of individual lettuce plant weights in the automated thinning plots was significant different from that of the hand thinning plots in lettuce (Fig. 2). Individual lettuce plant weights in the automated thinning treatment were greater than those in the hand thinning treatment in all three fields. Automated thinning resulted in higher individual plant weights by $6.6 \%, 17.1 \%$, and $13.2 \%$ in Expts. 1, 2, and 3, respectively (Fig. 2). At the same time, the percentage of plants within $10 \%$ of the mean plant weight increased from 

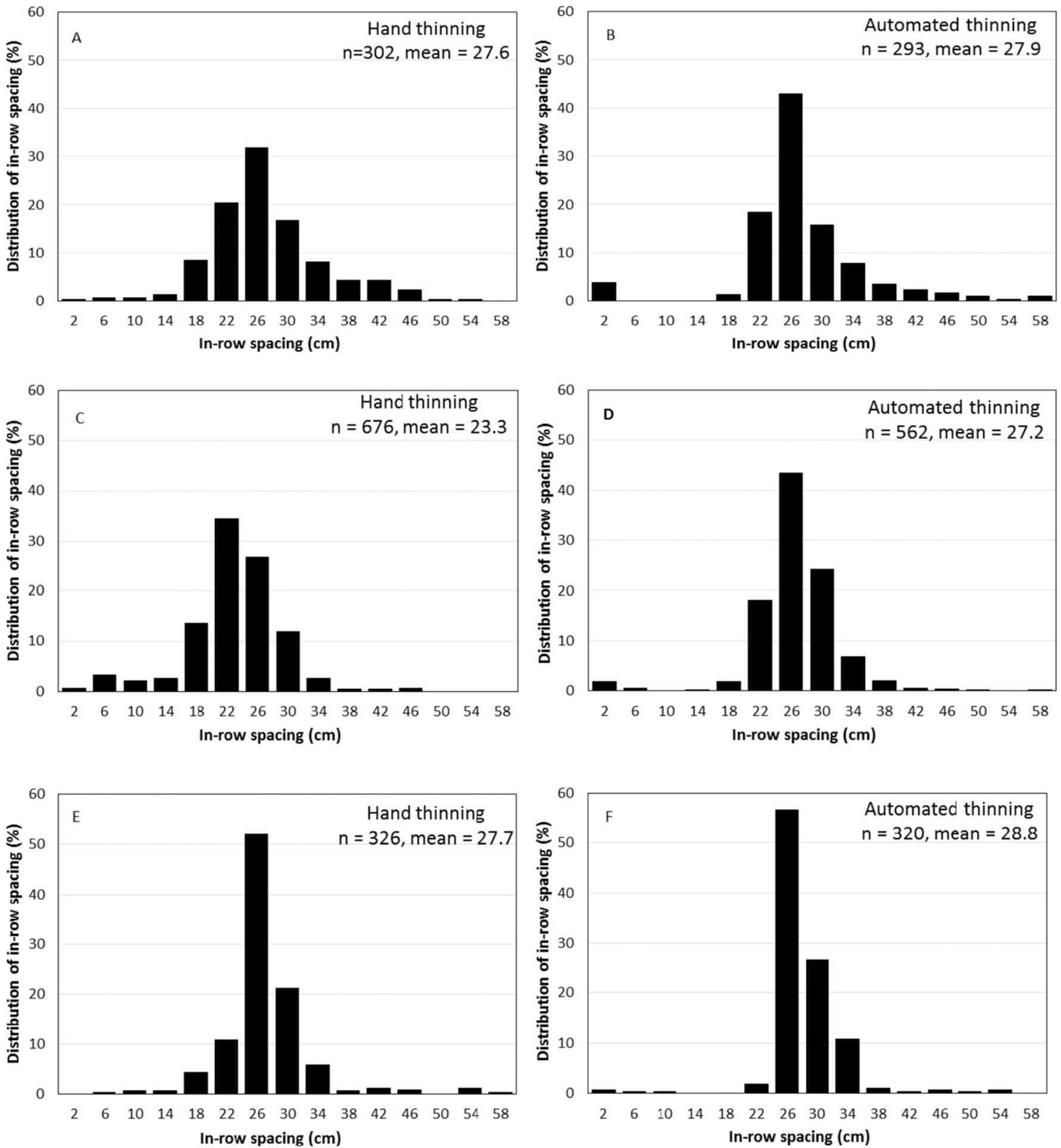

Fig. 1. Distribution of romaine lettuce plant in-row spacing affected by hand thinning and automated thinning in Expt. 1 (A and B), Expt. 2 (C and D), and Expt. 3 (E and F). The in-row spacing in the $x$-axis is the median of each column. For example, the column with $26 \mathrm{~cm}$ represents the percentage of plants that fall into in-row spacing of 24 to $28 \mathrm{~cm} ; 1 \mathrm{~cm}=0.3937$ inch.

$42 \%$ to $47 \%, 43 \%$ to $53 \%$, and $43 \%$ to $53 \%$ in Expts. 1, 2, and 3, respectively, indicating that automated thinning resulted in larger lettuce plant size and increased uniformity. As a result, heart weight in the automated thinning treatment was increased by $16.8 \%, 27.3 \%$, and $3.1 \%$ compared with hand thinning treatment in Expts. 1, 2, and 3, respectively (Fig. 3). The differences between automated thinning and hand thinning were significant as RMS values for testing the differences of two histograms in the same field experiments were $1.9,2.7$, and 2.0, respectively.
As with lettuce plant weight, the uniformity of lettuce heart weight was also increased by automated thinning.

Crop yield. Romaine heart yield was similar between the hand thinning and automated thinning treatments in Expts. 1 and 2 (Table 4). 

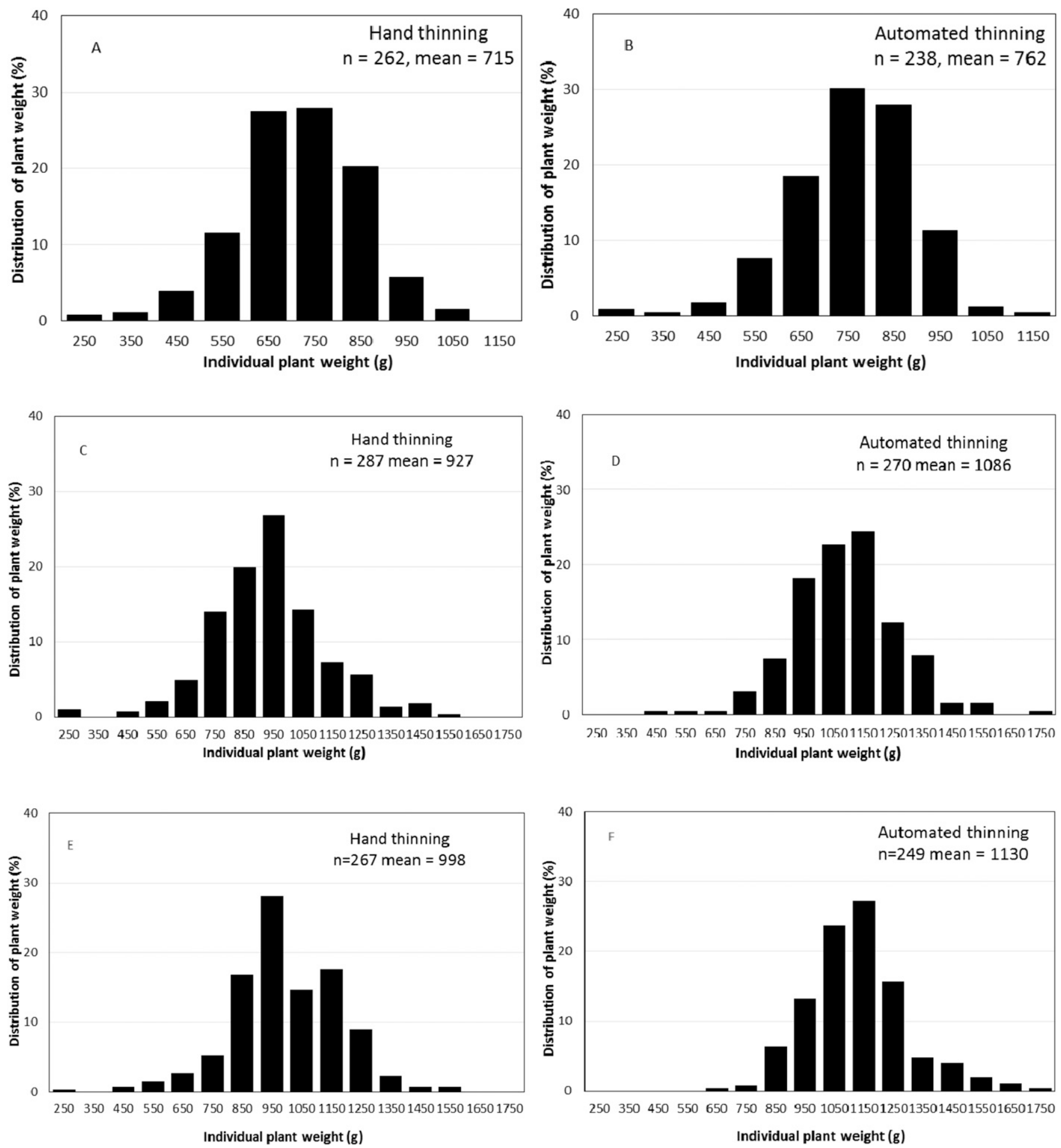

Fig. 2. Individual romaine lettuce plant weight at harvest affected by hand thinning and automated thinning in Expt. 1 (A and B), Expt. 2 (C and D), and Expt. 3 (E and F). The in-row spacing in the $x$-axis is the median of each column. For example, the column with $850 \mathrm{~g}$ represents the percentage of plants that fall into plant weight of 800 to $900 \mathrm{~g} ; 1 \mathrm{~g}=0.0353 \mathrm{oz}$.

Heart yield in the automated thinning treatment increased by $8.8 \%$ compared with the hand thinning treatment in Expt. 3. One of the reasons for the lack of significant yield benefit from automated thinning in Expts. 1 and 2 was that the hand thinning resulted in $4.1 \%$, $16.4 \%$, and $3.4 \%$ higher plant population in Expts. 1, 2, and 3, respectively (Table 4). At the same time, differences in heart size between the two treatments were not reflected in crop yield as lettuce yield was counted as boxes containing 12 bags, each with three romaine hearts.

\section{Discussion}

Many growers have visually noticed that lettuce thinned by automated thinners may grow more 

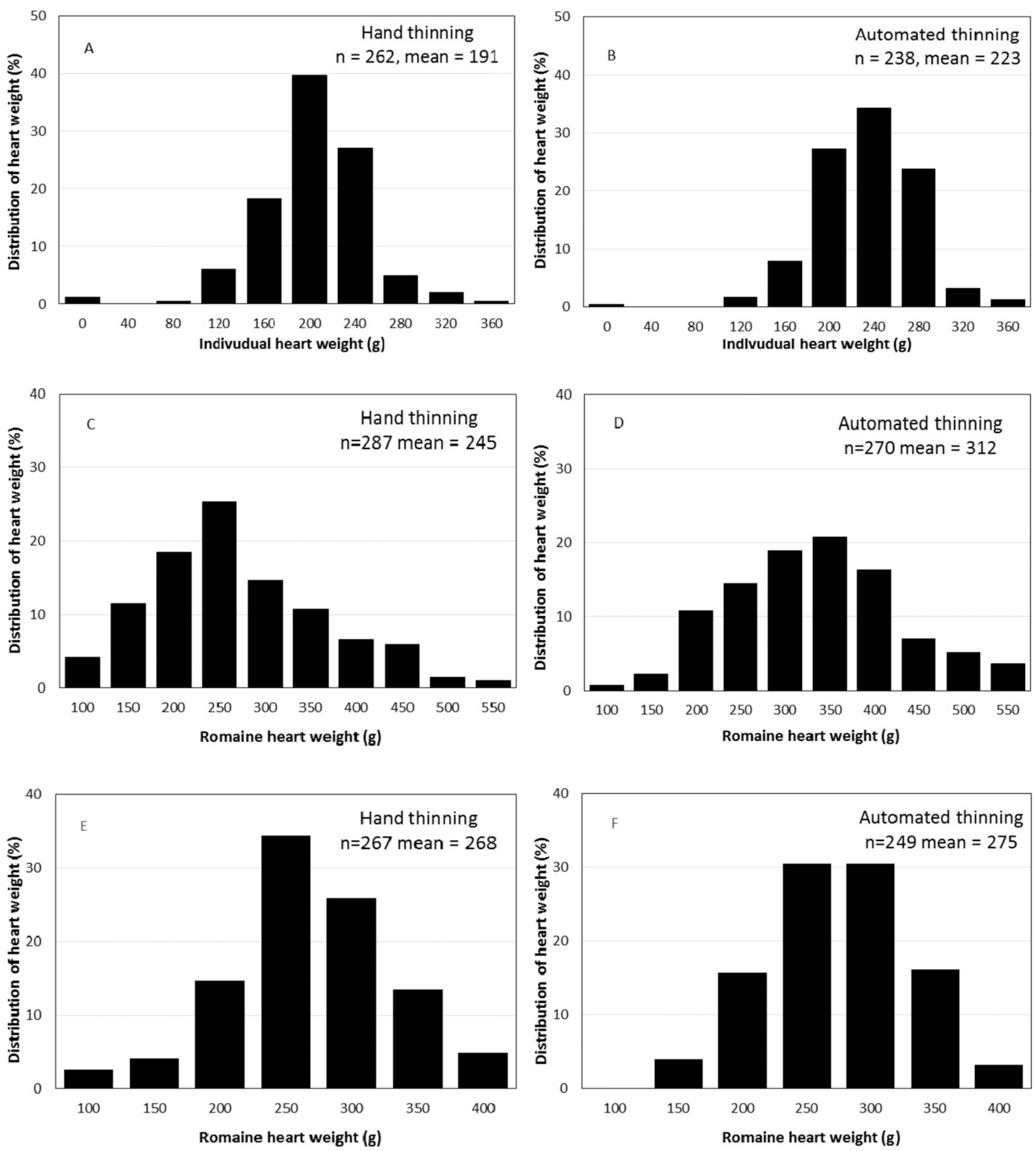

Fig. 3. Romaine lettuce heart weight at harvest affected by hand thinning and automated thinning in Expt. 1 (A and B), Expt. 2 (C and D), and Expt. 3 (E and F). The in-row spacing in the $x$-axis is the median of each column. For example, the column with $250 \mathrm{~g}$ represents the percentage of plants that fall into heart weight of 200 to $300 \mathrm{~g} ; 1 \mathrm{~g}=0.0353 \mathrm{oz}$.

vigorously than lettuce in hand thinned fields. Comparing automated thinning and hand thinning of lettuce in this study confirmed these observations. The lettuce plants in the automated thinning treatment were more uniform in in-row spacing and individual plant weight, and larger in plant and heart weight. However, yield benefits were not significant in two of the three experiments. One major reason for this is that plant population was higher after hand thinning than after automated thinning. Hand crews consistently thinned all three experimental fields with in-row spacing less than the targeted spacing of 12 inches, 
Table 4. Romaine heart yield affected by hand thinning and automated thinning in three field experiments in Imperial Valley, CA.

\begin{tabular}{llcc}
\hline Expt. & \multicolumn{1}{c}{ Treatment } & Yield (boxes/acre) & $\begin{array}{c}\text { Plant population } \\
(\mathbf{1 0 0 0} \text { plant/acre) }\end{array}$ \\
\hline 1 & Hand thinning & 864 & $43.0 \mathrm{a}^{\mathrm{x}}$ \\
& Automated thinning & 869 & $41.3 \mathrm{~b}$ \\
2 & Hand thinning & 1008 & $51.2 \mathrm{a}$ \\
& Automated thinning & 1017 & $44.0 \mathrm{~b}$ \\
3 & Hand thinning & $965 \mathrm{~b}$ & $43.0 \mathrm{a}$ \\
& Automated thinning & $1050 \mathrm{a}$ & $41.6 \mathrm{~b}$ \\
\hline
\end{tabular}

${ }^{z}$ Each box contains 12 bags each with three romaine hearts; 1 box $/$ acre $=2.4711$ boxes $/$ ha

${ }^{y} 1000$ plants $/$ acre $=2471.0538$ plants $/$ ha.

${ }^{x}$ Means with different letters in the same column of each experiment are significantly different via least significant difference at $P \leq 0.05$.

a phenomenon also observed by Ririe (1972). Another factor is that the yield was recorded simply as the number of boxes of bagged romaine hearts, which ignored plant weight and partially nullified the larger plant size, which resulted from the automated thinning treatment. However, the increased uniformity in in-row spacing resulted from automated thinning should enable growers to increase the number of plants per area without reducing plant uniformity, thus potentially increasing lettuce yield (Ririe, 1972). While the cost of hand thinning and automated thinning is similar, automated thinners provide a faster and improved alternative to hand thinning. It is worth noting that automated thinners are being continuously and rapidly improved by their developers.

Soil disturbance during hand thinning could be one major reason for smaller lettuce plants in the hand thinning treatment. During hand hoeing operations, wanted young lettuce plants can be injured when soil is moved to uproot unwanted plants, while automated thinning does not disturb the soil surface or otherwise impact plants. An estimated $10 \%$ to $15 \%$ of plants were partially covered by soil during hand thinning in this study. In addition to sublethal effects on lettuce plants, soil disturbance can make plants more susceptible to wind whipping (Kioke, 2011). Also disturbing the soil can increase evaporation rates by increasing the evaporative surface around the young plants. This can reduce moisture in the top layers of soil and subject plants to additional water stress when plant roots are shallow during a seedling's early growth stage.

Lack of crop uniformity can reduce the number of harvestable plants and marketable crop yield of lettuce (Ririe, 1972). Variation in lettuce plant size can be due to variety, biotic, tablishment (such as high temperature in September in southern California and southwestern Arizona), and/or thinning practices (Guzman, 1986). Automated thinning reduces plant size variability by increasing the uniformity of in-row spacing. In contrast, plant size variability increases as a direct result of hand thinning and as an indirect result of the abiotic stress caused by hand thinning.

The quality of hand thinning was significantly affected by soil type in this study. The heavy clay soil in field Expt. 2 made hand thinning more challenging. The growing points of many unwanted plants were not cut during thinning because of the hard soil surface, requiring a second thinning that was conducted 2 weeks later. However, the plant population in the hand thinning treatment was still $16.4 \%$ higher than the automated thinning treatment. While automated thinning is better than hand thinning and abiotic stresses during stand es- for all soil types, automated thinning appears to be especially beneficial when used with plants grown in heavy clay soils.

\section{Literature cited}

Bityukov, S., N. Krasnikov, A. Nikitenko, and V. Smirnova. 2013. A method for statistical comparison of histograms. 19 May 2015. <http://arxiv.org/abs/1302. $265 \operatorname{lv} 4>$

Guzman, V.L. 1986. Overcoming plant variability to improve yields and quality. Lettuce research workshop. Belle Glade EREC (Everglades Res. Educ. Ctr.) Res. Rpt. EV-1986-8. 24 Jan. 2015. <http:// ufdc.ufl.edu//UF00054456/00001>.

Koike, S. 2011. Wilting lettuce plants damaged by soil and wind factors. 24 Jan. 2015. <http://ucanr.edu/blogs/ b log core / postdetail.c f m ? postnum $=4719>$.

Lillywhite, J.M., J. Haskes, J. Libbin, and R. Herbon. 2004. Economic return to adoption on mechanical thinning: The case of New Mexico chile. New Mexico State Univ., New Mexico Chile Task Force Rpt. 14

Maboko, M.M. and C.P. Du Plooy. 2009. Effect of plant spacing on growth and yield of lettuce (Lactuca sativa L.) in a soilless production system. South African J. Plant Soil. 26:195-197.

Ririe, D. 1972. Minimum spacing studies for lettuce. Calif. Agr. 26(1):6-7.

Siemens, M.C., R. Herbon, R.R. Gayler, K.D. Nolte, and D. Brooks. 2012. Automated machine for thinning lettuceDevelopment and evaluation. Paper No. 12-1338169. 2012 Amer. Soc. Agr. Bio. Eng. Ann. Intl. Mtg., Dallas, TX, 29 July1 Aug. 2012.

Smith, R., M. Cahn, O. Daugovish, S. Koike, E. Natwick, H. Smith, K. Subbarao, E. Takele, and T. Turini. 2011. Leaf lettuce production in California. Univ. California Agr. Natural Resources Publ. 7216. 26 Jan. 2015. <http://anrcatalog.ucdavis. edu/pdf/7216.pdf $>$.

Taylor, J.E., D. Charlton, and A. YunezNaude. 2012. The end of farm labor abundance. Appl. Econ. Perspect. Policy 34:587-598. 